\title{
RESEARCH
}

Open Access

\section{Plasmodium falciparum in the southeastern Atlantic forest: a challenge to the bromeliad-malaria paradigm?}

Gabriel Zorello Laporta ${ }^{1,2^{*}}$, Marcelo Nascimento Burattini ${ }^{2,3}$, Debora Levy ${ }^{4}$, Linah Akemi Fukuya ${ }^{5}$, Tatiane Marques Porangaba de Oliveira' ${ }^{1}$ Luciana Morganti Ferreira Maselli, ${ }^{4,5}$, Jan Evelyn Conn ${ }^{6,7}$, Eduardo Massad ${ }^{2}$, Sergio Paulo Bydlowski ${ }^{4}$ and Maria Anice Mureb Sallum ${ }^{1}$

\begin{abstract}
Background: Recently an unexpectedly high prevalence of Plasmodium falciparum was found in asymptomatic blood donors living in the southeastern Brazilian Atlantic forest. The bromeliad-malaria paradigm assumes that transmission of Plasmodium vivax and Plasmodium malariae involves species of the subgenus Kerteszia of Anopheles and only a few cases of $P$. vivax malaria are reported annually in this region. The expectations of this paradigm are a low prevalence of $P$. vivax and a null prevalence of $P$. falciparum. Therefore, the aim of this study was to verify if $P$. falciparum is actively circulating in the southeastern Brazilian Atlantic forest remains.
\end{abstract}

Methods: In this study, anophelines were collected with Shannon and CDC-light traps in seven distinct Atlantic forest landscapes over a 4-month period. Field-collected Anopheles mosquitoes were tested by real-time PCR assay in pools of ten, and then each mosquito from every positive pool, separately for $P$. falciparum and $P$. vivax. Genomic DNA of $P$. falciparum or $P$. vivax from positive anophelines was then amplified by traditional PCR for sequencing of the $18 \mathrm{~S}$ ribosomal DNA to confirm Plasmodium species. Binomial probabilities were calculated to identify non-random results of the $P$. falciparum-infected anopheline findings.

Results: The overall proportion of anophelines naturally infected with P. falciparum was 4.4\% (21/480) and only $0.8 \%(4 / 480)$ with $P$. vivax. All of the infected mosquitoes were found in intermixed natural and human-modified environments and most were Anopheles cruzii $(22 / 25=88 \%, 18$ P. falciparum plus 4 P. vivax). Plasmodium falciparum was confirmed by sequencing in $76 \%(16 / 21)$ of positive mosquitoes, whereas $P$. vivax was confirmed in only 25\% (1/4). Binomial probabilities suggest that $P$. falciparum actively circulates throughout the region and that there may be a threshold of the forested over human-modified environment ratio upon which the proportion of $P$. falciparum-infected anophelines increases significantly.

Conclusions: These results show that $P$. falciparum actively circulates, in higher proportion than $P$. vivax, among Anopheles mosquitoes of fragments of the southeastern Brazilian Atlantic forest. This finding challenges the classical bromeliad-malaria paradigm, which considers P. vivax circulation as the driver for the dynamics of residual malaria transmission in this region.

Keywords: Atlantic forest, Anopheles, Forest fragment, Landscape, Malaria, Plasmodium falciparum, Transmission dynamics

\footnotetext{
* Correspondence: gabrielzorelo@usp.br

'Departamento de Epidemiologia, Faculdade de Saúde Pública da

Universidade de São Paulo, São Paulo, SP 01246-904, Brazil

¿2aboratório de Informática Médica (LIM 01), Faculdade de Medicina da

Universidade de São Paulo, São Paulo, SP 05405-000, Brazil

Full list of author information is available at the end of the article
} 


\section{Background}

The current paradigm of malaria epidemiology in the Brazilian Atlantic forest is based on the bromeliadmalaria model proposed by Lutz [1], Deane [2] and Gadelha [3], among others (e.g., [4]). The bromeliadmalaria hypothesis proposes that malaria in humans is caused by interactions between mosquito vectors of the subgenus Kerteszia, genus Anopheles (Anopheles cruzii as a primary vector), and Plasmodium vivax and Plasmodium malariae pathogens [4-6]. Bromeliad-malaria also includes simian malaria, a related cycle in which $A n$. cruzii can be infected by and transmit Plasmodium simium to howler monkeys (Aloutta spp.) [2,7]. Mosquito species included in the subgenus Kerteszia are adapted to bromeliad phytotelmata as habitats for their immature stages [8]. Consequently, humans in close contact with tropical rain forests with abundant bromeliad vegetation can be exposed to infective bites from females of those mosquitoes $[9,10]$.

Epidemics of malaria during the 1940s and 1950s in the southeastern Atlantic forest of Brazil have been primarily associated with the dynamics of bromeliad-malaria. Transmission was successfully controlled and malaria incidence decreased to a hypo-endemic level by an aggressive vector control program that included complete deforestation of areas where the incidence of the disease was high and Kerteszia species were the primary vectors. This massive effort to destroy bromeliads diminished the abundance of Kerteszia mosquitoes and eliminated the burden of malaria on humans [11]. Since that period, malaria has become residual with a very low level of transmission (Annual Parasite Index $[\mathrm{API}]<0.1$ ), and few autochthonous annual cases reported [12]. This situation led the Brazilian Ministry of Health to declare malaria nonendemic status for areas within the Atlantic forest after the 1970s [13,14]. However, residual malaria outbreaks in several localities within this biome [12,15] motivated investigations focused on the mosquito and parasite species associated with malaria transmission [10,16-20]. These research groups detected the involvement of species of the Kerteszia, Nyssorhynchus and Anopheles subgenera of genus Anopheles as vectors [10,20], and Alouatta and Cebus monkeys as potential reservoirs [16-19]. The high frequency of reactions against the repetitive epitopes of the circumsporozoite protein (CSP) of Plasmodium falciparum and $P$. vivax suggests that the infection of nonhuman primates $[16,17]$ by these Plasmodium species has been neglected. Taken together, these results indicate that the bromeliad-malaria hypothesis, which does not encompass the potential circulation of P. falciparum in areas of Atlantic forest, needs to be re-evaluated.

Recently, a cross-sectional study revealed a surprisingly high frequency $(5.14 \%, 57 / 1,108)$ of $P$. falciparum real-time PCR positivity in asymptomatic blood donors living or in close contact with forested regions of the southeastern Brazilian Atlantic forest biome [21]. The bromeliad-malaria paradigm would predict no P. falciparum infection and very low frequency of $P$. vivax infection in asymptomatic blood donors inhabiting forested areas of São Paulo state [22]. In fact, Mendrone et al. [22] suggested that the $P$. falciparum real-time PCR positivity found in asymptomatic blood donors [21] could be an artifact. However, another study proposed that alternative dynamics of Plasmodium transmission may have evolved and caused the unexpected high frequencies of P. falciparum DNA in humans, the high level of antibodies against CSP in monkeys and Plasmodiuminfected mosquito species other than Kerteszia [23]. The present study searched for $P$. falciparum circulating in mosquitoes captured in forest fragment areas within the Atlantic forest domain in southeastern São Paulo state. The major objectives of this study were to: 1) address the occurrence of Anopheles infection by $P$. falciparum and/or $P$. vivax; and, 2) verify the range of $P$. falciparum circulation in the biome, scrutinizing possible relationships between frequency of $P$. falciparum infection in anophelines and different grades of intermixed natural and human-modified environments.

\section{Methods}

\section{Anopheles mosquito collection}

Field collections were conducted in seven localities situated within an area of 11,000 sq $\mathrm{km}$ in the fragmented remains of the Atlantic forest in southeastern São Paulo state. To sample mosquitoes, a landscape-based, crosssectional design was adopted as follows: landscapes 1-B and $1-\mathrm{C}$ - predominantly natural vegetation; landscapes 1-A, 3, 4, and 5 - natural vegetation intermixed with rural and urban areas; landscape 2 - predominantly human-modified environment. The characterization of features (e.g., natural vegetation, open areas) in each landscape was performed by supervised image classification technique in ArcGIS 10 Spatial Analyst ${ }^{\mathrm{Tm}}$ Image Classification tool. Accordingly, a known setting of trained pixels was applied in order to convert multiband Landsat 5 TM into a single band image with different categories of landscape features. The conversion was based on differential spectral sunlight responses to distinct landscapes. Forest fragments in multiband Landsat 5 TM images showed low pixel values in blue and red bands, because of the high absorption in these wavelengths for photosynthesis. On the contrary, forest reflectance was high for green and near infrared bands. Exposed soil in rural areas had low pixel values for blue, green and red bands, whereas water had high pixel values for the blue band only. Urban areas had a mixture of reflectance and combinations of spectrally distinct land cover categories. The proportion of each land cover 
type (i.e., natural vegetation, rural and urban areas) within each landscape was estimated with the aid of FRAGSTATS version 4 [24]. In Figure 1, dark green areas correspond to forested areas; light green areas correspond to Atlantic coast restinga; and tiny brownish areas correspond to mangrove. White areas correspond to human modified environments and pink areas represent urban areas. See Figure 1 for details.

Mosquitoes were captured from August to November 2012, using CDC-LT (Centers for Disease Control light traps), with and without Octenol plus $\mathrm{CO}_{2}$ as attractants, and Shannon traps. The location of traps in the field was planned to capture mosquitoes in transition zones (forest fringes and forest edges), inside forest fragments (i.e., patches of conspicuous natural vegetation) and in anthropogenic areas (i.e., either rural or urban), in each landscape.

Six CDC traps were distributed in three localities in each landscape: a) approximately 50 meters inside the forest; b) at the forest edge; and c) in the open area approximately 50 meters from the forest edge. See Figure 2 for details of the trap locations in each landscape.

Specifically, three CDC-LT were placed inside the forest: one CDC-LT with Octenol plus $\mathrm{CO}_{2}$ and one CDC-LT without attractant were installed 1.5 metres above the ground ( 20 metres apart) and one in the tree canopy. Two CDC-LTs without attractant were installed at the forest edge: one at the level of the tree canopy and one 1.5 metres above the ground. Finally, one CDC-LT without attractant was installed in the open area, 1.5 metres above the ground. For all CDC-LT traps the period of sampling extended from 18:00-06:00 h, when they were collected for analysis (see Additional files 1 and 2 for details). This sampling procedure was repeated the following day in each landscape, totaling 12 CDC-LTs and 144-hour-effort. In landscapes 1-B and 1-C only CDC-LT traps were used.

Additionally, collections with Shannon traps were performed from 17:00-05:00 h, totaling 12-hour-effort, in landscapes 1-A, 2, 3 and 4. In landscape 5, Shannon trap was used in a three-hour-effort, from 17:00-20:00 h (see Additional files 1 and 2 for details).

\section{Anopheles identification}

Each mosquito was morphologically identified using a standard dichotomous key [25]. A subsample of individuals, from each species collected, was identified by DNA sequencing of the COI barcode region of the mitochondrial DNA genome, for morphological identification confirmation, according to Foster et al. [26] protocols. Homology between the COI mtDNA sequences from Anopheles individuals generated in this study and those available in GenBank was assessed using the nucleotide BLAST search algorithm [27].
Template DNA from both non-infected Anopheles species and Anopheles infected with Plasmodium spp. was stored at $-70^{\circ} \mathrm{C}$ in a reference entomological collection, the Coleção Entomológica de Referência, Universidade de São Paulo, Brazil, for future reference.

\section{Genomic DNA extraction}

DNA was extracted from each Anopheles specimen individually using a salting-out method [28]. The head and thorax of each Anopheles individual was separated from the abdomen using a fine entomological pin as suggested by Foley et al. [29]. Each head and thorax was then mixed in $500 \mu \mathrm{L}$ TEN buffer $(2 \mathrm{mM}$ Tris- $\mathrm{HCl}, \mathrm{pH}$ 8.0, containing $0.5 \mathrm{mM}$ EDTA and $5 \mathrm{mM} \mathrm{NaCl}$ ) with $5 \mu \mathrm{L}$ $10 \%$ SDS (sodium dodecyl sulphate) and $3-\mu \mathrm{L}$ proteinase $\mathrm{K}(20 \mathrm{mg} / \mathrm{mL})$. The mixture was homogenized with a tissue tearor (model 985370-395 Biospec products) until complete insect disruption and incubated for $1 \mathrm{hr}$ at $56^{\circ} \mathrm{C}$. Then, $150 \mu \mathrm{L}$ saturated $\mathrm{NaCl}(5 \mathrm{M})$ was added and the mixture was stirred vigorously for $30 \mathrm{sec}$. After centrifugation at 5,000 rpm for $10 \mathrm{~min}$ at room temperature $\left(18-25^{\circ} \mathrm{C}\right)$, the supernatant was transferred to a $1.5-\mathrm{ml}$ plastic vial containing $600 \mu \mathrm{L}$ of cold isopropanol. This tube was inverted several times to aid DNA precipitation, and was kept at $-20^{\circ} \mathrm{C}$ overnight to increase precipitation. The tube containing DNA was spun at $12,000 \mathrm{rpm}$ for $10 \mathrm{~min}$ at $4^{\circ} \mathrm{C}$. The pellet was then washed four times with 70\% ethanol, and centrifuged at $5,000 \mathrm{rpm}$ for $5 \mathrm{~min}$ at room temperature to remove any excess salt. DNA was dried for $20 \mathrm{~min}$ in a vacuum centrifuge AES1010 Speed Vac (Savant, USA), and resuspended in $20 \mu \mathrm{L}$ TE $(2 \mathrm{mM}$ Tris- $\mathrm{HCl}, \mathrm{pH}$ 8.0, $0.5 \mathrm{mM}$ EDTA). The total amount of genomic DNA obtained from each individual mosquito head and thorax was quantified using a NanoDrop (ND-1000 UV-vis Spectrophotometer).

\section{Real-time PCR assay by hydrolysis probe}

A standardized real-time PCR protocol adapted from [30] and previously used in our laboratory [21] was employed to detect $P$. falciparum and $P$. vivax DNA in Anopheles specimens. The specificity and sensitivity of this protocol was verified utilizing a 10-fold serial dilution of different positive controls: 1) a laboratory-culture of P. falciparum to test the specificity of the hydrolysis probe; 2) a blood sample obtained from a patient infected with $P$. vivax to test the specificity of the hydrolysis probe, 3) genomic DNA extracted from one head plus thorax of Anopheles gambiae infected with P. falciparum to test the sensitivity of the hydrolysis probe and, finally, 4) a mixture of DNA obtained from a patient with $P$. vivax and genomic DNA extracted from the head and thorax of one non-infected Anopheles mosquito (adult emerged in laboratory from field collected pupa) to test the sensitivity of the hydrolysis probe. A 

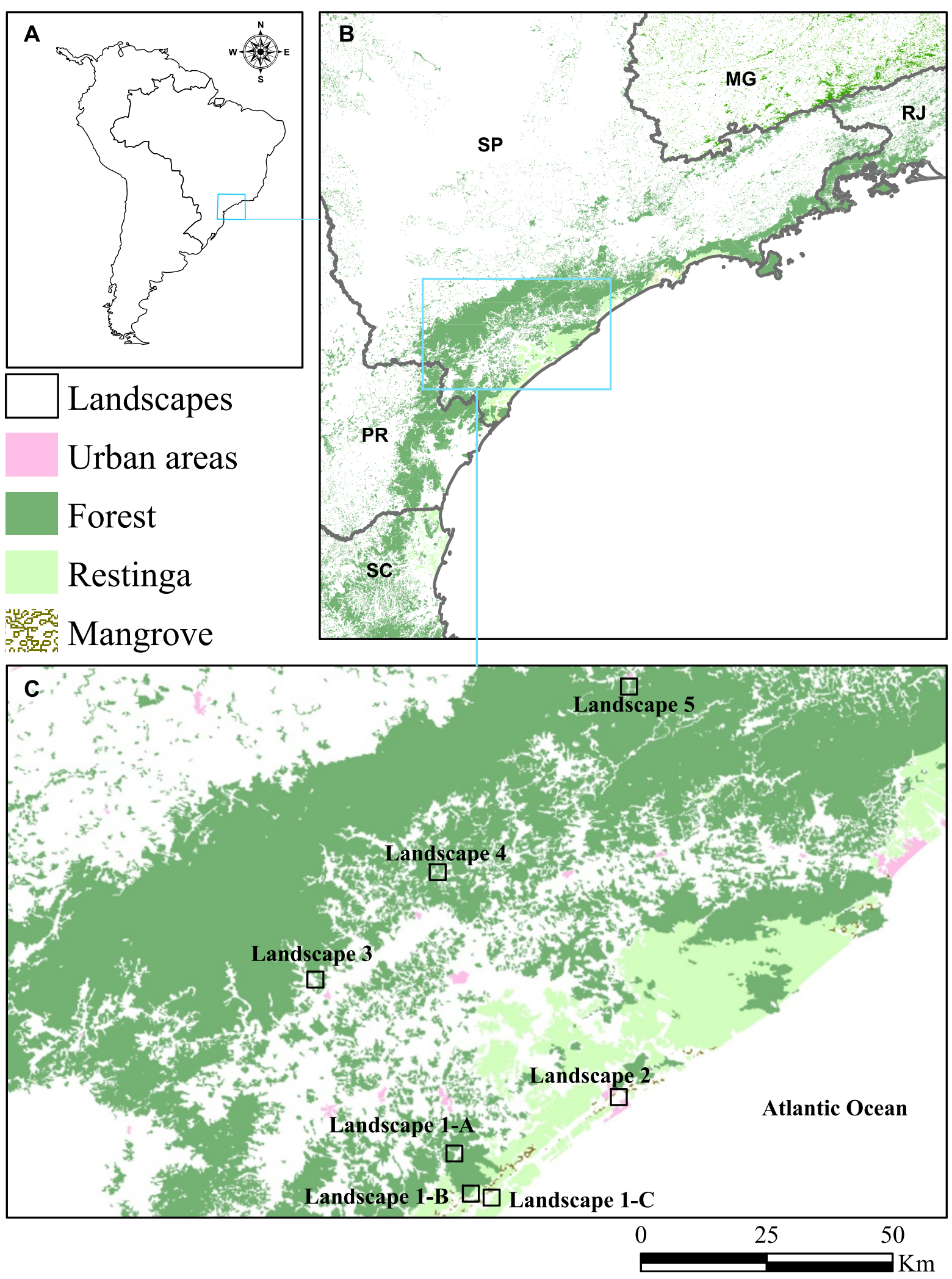

Figure 1 (See legend on next page.) 
(See figure on previous page.)

Figure 1 Study region and design. A) South America. B) Southeastern Brazilian Atlantic forest. SP: São Paulo state, MG: Minas Gerais state, RJ: Rio de Janeiro state, PR: Paraná state, SC: Santa Catarina state. C) Landscapes 1-5 (10 sq km) representing spatial scale in which dynamics of malaria transmission can occur, given the estimated home ranges of vectors and parasites. Source: SOS Mata Atlântica, Instituto Nacional de Pesquisas Espaciais (INPE), 2008.

PCR amplification product was obtained only when specific Plasmodium species were present in the reaction; no product was detected in samples without specific parasites, or when Anopheles stephensi infected with Plasmodium berghei was tested. The lack of crossamplification between different reactions demonstrated that each was specific for the Plasmodium species tested.
The samples were tested in pools of genomic DNA from 10 Anopheles individuals. Each pool was made with $100 \mathrm{ng}$ of DNA extracted from each mosquito and the real-time PCR test used $300 \mathrm{ng}$ of the pooled DNA. After this, each mosquito from a positive pool was individually retested using $30 \mathrm{ng}$ of DNA. Samples of laboratory-cultured $P$. falciparum and of human blood
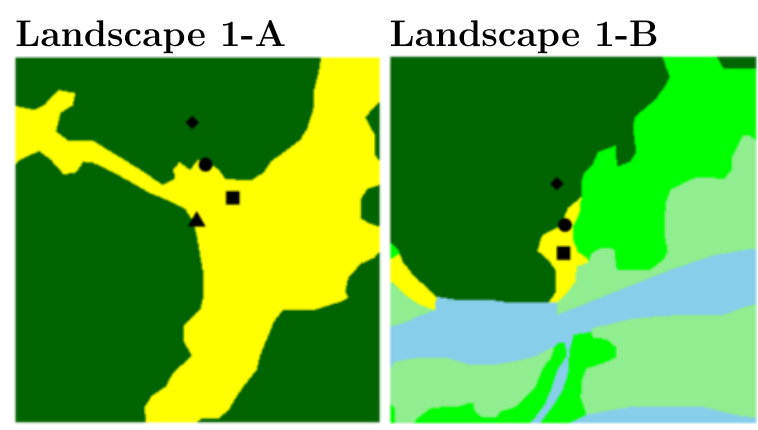

Landscape 1-C

Landscape 2

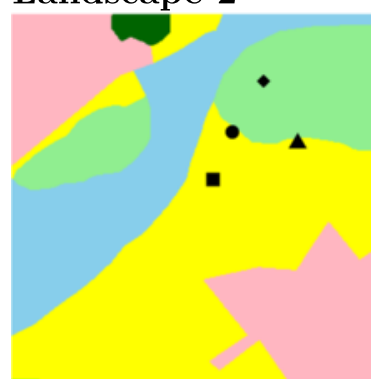

Landscape 5
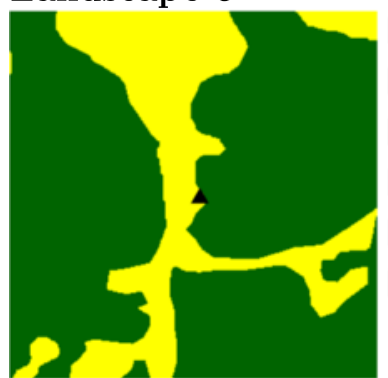

Landscape 3

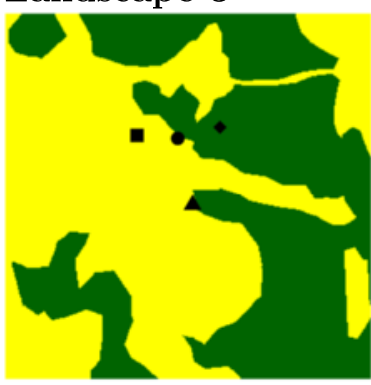

Composition

Water

Forest

Restinga

Mangrove

Urban area

Rural area

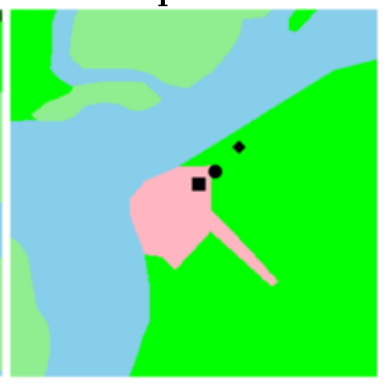

Landscape 4

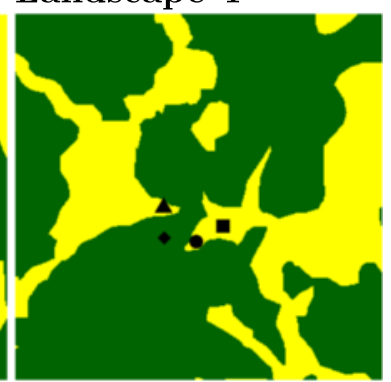

Traps

$\Delta$ Shannon trap

- CDC-light trap A

- CDC-light trap B

- CDC-light trap C

Landscape scale: $10 \mathrm{~mm} \sim 60 \mathrm{~m}$

Trap diagrams are out of scale

Figure 2 Landscape features and trap locations. Landscape 1-A - Esteiro do Morro, natural vegetation (65.37\%) and rural (34.63\%). Landscape 1-B - Taki, natural vegetation plus water (97.49\%) and rural (2.51\%). Landscape 1-C - Pedrinhas, natural vegetation plus water (94.48\%) and urban (5.52\%). Landscape 2 - Boqueirão Norte, natural vegetation plus water (38.94\%), rural (38.90\%) and urban (22.16\%). Landscape 3 - Eldorado, natural vegetation (44.66\%) and rural (55.34\%). Landscape 4 - Sete Barras, natural vegetation (65.37\%) and rural (34.63\%). Landscape 5 - Tapiraí, natural vegetation (74.99\%) and rural (25.01\%). CDC-light trap A: one CDC-LT with attractants and one CDC-LT 1.5-m above the ground and one CDC-LT in the tree canopy; CDC-light trap B: one at the level of the tree canopy and one 1.5-m above the ground; CDC-light trap C: one CDC-LT 1.5-m above the ground. 
samples positive for $P$. vivax were used as positive controls for the real-time PCR reactions. Each sample was tested in duplicate and positive samples were retested in two distinct real-time PCR reactions. Each real-time PCR reaction had a final volume of $12.5 \mu \mathrm{L}$ with $5 \mu \mathrm{L}$ from the final $\mathrm{ddH}_{2} \mathrm{O}$ diluted field sample, $6.25 \mu \mathrm{L}$ of the $\operatorname{TaqMan}^{\text {Tx }}$ Gene Expression Master Mix (Applied Biosystems, Foster City, CA, USA) and $1.25 \mu \mathrm{L}$ of $300 \mathrm{nM}$ forward primer, $300 \mathrm{nM}$ reverse primer for either P. vivax or P. falciparum and $200 \mathrm{nM}$ of TaqMan ${ }^{\mathrm{Tm}}$ probe. Primers and $\mathrm{TaqMan}^{\mathrm{Tn}}$ probes are described elsewhere [21,30]. Real-time PCR amplification was achieved using a 7500 FAST real time PCR system (Applied Biosystems, Foster City, CA, USA) with a programme involving two thermal cycler holds. Conditions were $50^{\circ} \mathrm{C}$ for $2 \mathrm{~min}$ and $95^{\circ} \mathrm{C}$ for $10 \mathrm{~min}$, followed by 50 cycles of amplification $\left(95^{\circ} \mathrm{C}\right.$ for $15 \mathrm{sec}$ and $60^{\circ} \mathrm{C}$ for $1 \mathrm{~min})$. Results were analyzed using the 7500 software v.2 0.5 (Applied Biosystems, Foster City, CA, USA).

\section{Plasmodium PCR amplification and DNA sequencing}

To confirm the presence of either $P$. falciparum or P. vivax DNA in Anopheles mosquitoes, the genomic DNA mix (mosquito plus Plasmodium DNA) obtained from the head and thorax of each field-collected mosquito positive in the real-time PCR was checked separately, employing a single template PCR amplification strategy. Each DNA mix was tested only for the Plasmodium species identified in the real-time PCR. PCR amplification was carried out using the same set of speciesspecific primers employed for the real-time PCR, without the TaqMan ${ }^{\text {tax }}$ probes. The pairs of primers FAL-F (5' CT TTTGAGAGTTTTGTTACTTTGAGTAA 3'), FAL-R (5' TATTCCATGCTGTAGTATTCAAACACAA 3') were used to amplify a $\sim 96$ base pair fragment of the $18 \mathrm{~S}$ rDNA region of $P$. falciparum, and the pair VIV-F (5' ACG CTTCTAGCTTAATCCACATAACT 3'), VIV-R (5' ATT TACTCAAAAGTAACAAGGACTTCCAAGC 3') amplified a $\sim 140$ base pair fragment of $P$. vivax. The PCR was performed in a final volume of $25 \mu \mathrm{L}$ containing $1 \mu \mathrm{L}$ DNA extraction solution, $12.5 \mu \mathrm{L}$ reagent TaqMan ${ }^{\text {Tw }}$ Gene Expression Master Mix (Applied Biosystems, Foster City, CA, USA) with $0.3 \mu \mathrm{M}$ forward primer and $0.3 \mu \mathrm{M}$ reverse and the remaining volume of $\mathrm{ddH}_{2} \mathrm{O}$. The PCR thermal conditions were the same as those employed for the realtime PCR. The PCR products were purified by DNA Clean \& Concentrator ${ }^{\mathrm{Tm}}$ kit (Zymo Research), and sequenced in both directions, using Sanger technology [31], with the same set of primers employed for amplification. Sequencing reactions were carried in a total volume of $10 \mu \mathrm{L}$ containing $20 \mathrm{ng}$ of the purified PCR product, $0.5 \mu \mathrm{L}$ BigDye $^{\mathrm{m} x}$ Terminator Ready Reaction Mix, $2 \mu \mathrm{L}$ of $1 \times$ Sequencing Buffer (Applied Biosystems), 3.6 pmol of reverse or forward primers and the remaining volume of ultrapure $\mathrm{H}_{2} \mathrm{O}$.
Sequencing reactions were purified in Sephadex G50 columns (GE Healthcare), analyzed on an ABI Prism 3130 - Avant Genetic Analyzer (Applied Biosystems, Foster City, CA, USA), and edited using Sequencher ${ }^{\mathrm{ru}}$ version 5.1 (Gene Codes Corporation, Ann Arbor, USA).

\section{Binomial test}

In order to detect non-random outcomes of the obtained results per landscape, it was performed a binomial distribution analysis with the anopheline-P. falciparum infection data. Considering the overall prevalence of anophelineP. falciparum infection obtained in the present study (see Results) as the a priori probability, two probabilities were calculated assuming the binomial distribution. First, it was calculated the probability of having at least one positive anopheline in the sample obtained. From this probability, the statistical power $(1-\beta)$ of each sample in detecting $P$. falciparum infection in the corresponding landscape, or species, or trap was estimated. Then, it was calculated the exact probability of finding the number of positive mosquitoes $(\mathrm{k})$ among the total tested (n) per landscape, species, or trap. If this probability was under the adopted level of significance then it was used as evidence of a non-random outcome, i.e., below or above the expected result (i.e., the aforementioned overall prevalence). The significance level of 0.05 and the power of the test of 0.8 were adopted [32].

\section{Results}

A total of 921 Anopheles specimens were captured. A subsample of 480 anophelines (over the 921 captured) was used to the real-time PCR testing. The subsample selection strategy was oriented to proven vectors in the region (e.g., An. cruzii, An. bellator and An. marajoara) [33] plus others that were found infected recently (e.g., An. strodei, An. triannulatus, An. fluminensis) $[10,20]$ or other abundantly captured species (e.g., An. galvaoi, An. mediopunctatus). Table 1 shows the absolute and relative frequencies of Anopheles species captured.

Twenty-five specimens were infected with Plasmodium parasites, for an overall prevalence of $5.2 \%(25 / 480)$. As related to the malaria parasites, 21 out of $25(84 \%)$ were positive for $P$. falciparum, contrasting with only four out $25(16 \%)$ which were positive for $P$. vivax. None of the mosquito samples was tested for P. malariae, in spite of the traditional acknowledgement of this species participation in the bromeliad-malaria paradigm. Nevertheless, between 1980 and 2007, only five cases were attributed to P. malariae (less than $1 \%, 5 / 821$ cases) in São Paulo state [34].

Anopheles cruzii was the species with the highest infectivity $(22 / 260,8.5 \%)$, and represented almost the totality of infected anophelines found $(22 / 25,88 \%)$. There was a preponderance of $P$. falciparum infection among them $(18 / 22,82 \%$, of $P$. falciparum and $4 / 22,18 \%$, of 
Table 1 Absolute (n) and relative frequency (\%) of field collected Anopheles specimens per landscape, Atlantic forest, Brazil, August-November 2012

\begin{tabular}{|c|c|c|c|c|c|}
\hline \multirow[t]{2}{*}{ Landscape } & \multirow[t]{2}{*}{ Traps } & \multirow[t]{2}{*}{ Species } & \multicolumn{2}{|c|}{ Frequency } & \multirow{2}{*}{$\begin{array}{l}\text { Period of } \\
\text { collection }\end{array}$} \\
\hline & & & $n$ & $\%$ & \\
\hline \multirow{8}{*}{$1-A$} & Shannon & An. (Ano.) fluminensis ${ }^{a}$ & 4 & 0.43 & Mid October \\
\hline & CDC-LT & An. (Ano.) intermedius & 2 & 0.22 & Late August \\
\hline & Shannon & An. (Ano.) intermedius ${ }^{a}$ & 12 & 1.30 & Mid October \\
\hline & CDC-LT & An. (Ker.) bellator & 1 & 0.11 & Late August \\
\hline & CDC-LT & An. (Ker.) cruzii & 2 & 0.22 & Late August \\
\hline & Shannon & An. (Ker.) cruzii ${ }^{a}$ & 4 & 0.43 & Mid October \\
\hline & Shannon & An. (Nys.) strodei s.s. ${ }^{a}$ & 100 & 10.86 & Mid October \\
\hline & Shannon & An. (Nys.) triannulatus ${ }^{a}$ & 21 & 2.28 & Mid October \\
\hline$\underline{\text { Subtotal }}$ & & & 146 & 15.85 & \\
\hline \multirow{2}{*}{$1-B$} & CDC-LT & An. (Ker.) bellator & 5 & 0.54 & Mid August \\
\hline & CDC-LT & An. (Ker.) cruzii & 27 & 2.94 & Mid August \\
\hline Subtotal & & & 32 & 3.48 & \\
\hline \multirow{2}{*}{$1-C$} & CDC-LT & An. (Ano.) mediopunctatus & 19 & 2.06 & Mid August \\
\hline & CDC-LT & An. (Ker.) cruzii & 1 & 0.11 & Mid August \\
\hline Subtotal & & & 20 & 2.17 & \\
\hline \multirow{4}{*}{2} & Shannon & An. (Ano.) intermedius ${ }^{a}$ & 1 & 0.11 & Mid September \\
\hline & CDC-LT & An. (Ano.) mediopunctatus & 12 & 1.30 & Late August \\
\hline & Shannon & An. (Ano.) mediopunctatus ${ }^{\mathrm{a}}$ & 8 & 0.87 & Mid September \\
\hline & Shannon & An. (Nys.) albitarsis s.s. ${ }^{a}$ & 14 & 1.52 & Mid September \\
\hline \multirow[t]{5}{*}{ Subtotal } & & & 35 & 3.80 & \\
\hline & Shannon & An. (Ano.) intermedius & 14 & 1.52 & Late October \\
\hline & CDC-LT & An. (Ano.) mediopunctatus & 2 & 0.22 & Late August \\
\hline & Shannon & An. (Ano.) mediopunctatus ${ }^{a}$ & 51 & 5.54 & Late October \\
\hline & CDC-LT & An. (Ker.) cruzii & 1 & 0.11 & Late August \\
\hline \multirow[t]{5}{*}{3} & Shannon & An. (Ker.) cruzii & 19 & 2.06 & Late October \\
\hline & Shannon & An. (Nys.) albitarsis s.s. ${ }^{a}$ & 2 & 0.22 & Late October \\
\hline & Shannon & An. (Nys.) galvaoi & 147 & 15.96 & Late October \\
\hline & Shannon & An. (Nys.) oswaldoi s.l. & 13 & 1.41 & Late October \\
\hline & Shannon & An. (Nys.) triannulatus & 14 & 1.52 & Late October \\
\hline \multirow[t]{5}{*}{ Subtotal } & & & 263 & 28.56 & \\
\hline & Shannon & An. (Ano.) intermedius & 2 & 0.21 & Mid September \\
\hline & CDC-LT & An. (Ano.) mediopunctatus & 1 & 0.11 & Late August \\
\hline & Shannon & An. (Ano.) mediopunctatus ${ }^{\mathrm{a}}$ & 1 & 0.11 & Mid September \\
\hline & CDC-LT & An. (Ker.) cruzii & 1 & 0.11 & Late August \\
\hline \multirow[t]{5}{*}{4} & Shannon & An. (Ano.) mediopunctatus ${ }^{\mathrm{a}}$ & 3 & 0.32 & Mid September \\
\hline & Shannon & An. (Nys.) albitarsis s.s. & 14 & 1.52 & Mid September \\
\hline & Shannon & An. (Nys.) galvaoi & 58 & 6.30 & Mid September \\
\hline & Shannon & An. (Nys.) oswaldoi s.l. & 8 & 0.87 & Mid September \\
\hline & Shannon & An. (Nys.) triannulatus & 39 & 4.24 & Mid September \\
\hline Subtotal & & & 127 & 13.79 & \\
\hline
\end{tabular}


Table 1 Absolute (n) and relative frequency (\%) of field collected Anopheles specimens per landscape, Atlantic forest, Brazil, August-November 2012 (Continued)

\begin{tabular}{|c|c|c|c|c|c|}
\hline \multirow{4}{*}{5} & Shannon & An. (Ker.) cruzii & 251 & 27.25 & Late November \\
\hline & Shannon & An. (Nys.) near pristinus & 4 & 0.43 & Late November \\
\hline & Shannon & An. (Nys.) strodei s.s. ${ }^{a}$ & 40 & 4.34 & Late November \\
\hline & Shannon & An. (Nys.) triannulatus & 3 & 0.33 & Late November \\
\hline Subtotal & & & 298 & 32.35 & \\
\hline Total & & & 921 & 100 & \\
\hline
\end{tabular}

${ }^{a}$ Morphological identification confirmed by DNA COI barcode sequences.

P. vivax). The remaining three anophelines were infected with P. falciparum, being one An. strodei, one An. triannulatus, and one An. galvaoi. Table 2 shows the amount of anophelines tested and positive in each landscape studied.

Table 2 shows that eight out of the twenty-five anopheline samples that tested positive with real-time PCR for Plasmodium did not amplify parasite DNA ( 3 P. vivax and 5 P. falciparum) in conventional PCR (Additional file 3). From these 17 samples, 16 (15 of P. falciparum and 1 of $P$. vivax) had their fragment of the $18 \mathrm{~S}$ rDNA gene sequenced and submitted to BLAST analysis. The P. falciparum fragments shared $99 \%$ similarity with P. falciparum sequences previously associated with wild monkeys (Lagothrix cana cana, KC906727 and Alouatta puruensis, KC906718; [35]) and 98\% similarity with Callicebus brunneus (KC906722; [35]), from the Amazon region of Brazil. In contrast, the $18 \mathrm{~S}$ rDNA sequence of $P$. vivax shared $100 \%$ similarity with two samples sequenced from human isolates in India (JQ627157 and JQ627156). Morphological identification of the 25 anophelines positive for Plasmodium infection was confirmed using DNA sequences of the barcode region of the COI mitochondrial gene (GenBank accession numbers in Additional file 4).

The distribution of infected mosquitoes was neither spatially nor taxonomically random. Table 3 shows the results of the specific binomial probabilities of positive findings for landscapes, Anopheles species, and traps.

From Table 3, it can be seen that in 3/7 different landscapes $P$. falciparum-infected anophelines were found, for an overall prevalence of $4.4 \%$ (21/480). However, it was not possible to exclude active $P$. falciparum circulation all over the region, as the power of the test was consistently below the threshold of $80 \%$ for the negative landscapes. In addition, in landscape 5 (natural vegetation intermixed with rural areas, in a ratio 3:1) the prevalence of infected anophelines found was higher than expected. On the other hand, in landscape 3 (natural vegetation intermixed with rural areas, in a ratio 0.8:1), a more intensively human modified environment, the prevalence of infected anophelines found was lower than expected. Finally, in landscape 1-A (natural vegetation intermixed with rural areas, in a ratio 1.9:1), representing an intermediary forest covered environment comparing to landscapes 5 (more forested) and 3 (less forested), the prevalence of infected anophelines found was not significantly apart from the expected overall prevalence for the region. These findings could suggest that there may be a negative gradient between human modified environments and prevalence of P. falciparum among anophelines (specifically An. cruzii) in this region. This new hypothesis shall be tested in a future and properly designed study.

Notwithstanding, all infected anophelines were collected in Shannon traps, which were not used in landscapes 1-B and 1-C (predominantly natural vegetation intermixed with rural areas). In contrast, CDC-LTs collected only 76 female anophelines, representing only $8.3 \%$ of the total captured. Half (38/76) of the CDC-LT-collected Anopheles were tested, according to the criteria defined before, and no specimen was positive for either $P$. vivax or $P$. falciparum DNA (power of the test $=0.87$, considering the overall prevalence of $5.2 \%$ ). Maybe this is because CDC-LT captures females not searching for a blood meal and those are predominantly young and nulliparous ones in the natural environment.

\section{Discussion}

Results of the present study showed that P. falciparum and $P$. vivax are present and infect anophelines in forestfragmented areas of the southeastern Atlantic forest where bromeliads are common and dense [36]. Lutz [1] in 1903 proposed the involvement of Kerteszia species (An. cruzii identified as $A n$. lutzi) in the epidemiology of malaria in the southeastern Atlantic forest. Later, Downs and Pittendrigh [37] proposed the term "bromeliad-malaria" for the transmission involving species of the subgenus Kerteszia. In the following years, the bromeliad-malaria explanation was largely adopted by malariologists, and thus became a paradigm to explain the dynamics of residual malaria that still occur in areas of the Atlantic forest where Anopheles (Kerteszia) species are abundant and are primary vectors of $P$. vivax and P. malariae [2,3]. The larval habitats of the majority of the species in subgenus Kerteszia are bromeliad phytotelmata [25,38], except for Anopheles bambusicolus that is associated with the internodes of bamboo plants 
Table 2 Anopheles species, number of mosquitoes tested positive for Plasmodium DNA/number of individuals tested for infection (+/n), frequency (\%) of infected Anopheles, PCR method (real-time and conventional PCR) and the parasite species per landscape, Atlantic forest, Brazil, August-November 2012

\begin{tabular}{|c|c|c|c|c|}
\hline Landscape & Species $^{a}$ & Real-time PCR +/n (\%) & PCR +/n (\%) & Parasite species $^{\mathbf{b}}$ \\
\hline \multirow{5}{*}{$1-\mathrm{A}$} & An. cruzii & $0 / 6(0.0)$ & - & - \\
\hline & An. fluminensis & $0 / 3(0.0)$ & - & - \\
\hline & An. strodei & $1 / 72(1.4)$ & $0 / 1(0.0)$ & P. falciparum \\
\hline & An. triannulatus & $1 / 12(8.3)$ & $0 / 1(0.0)$ & P. falciparum \\
\hline & Subtotal & $2 / 93(2.15)$ & $0 / 2(0.0)$ & - \\
\hline \multirow{3}{*}{$1-B$} & An. cruzii & $0 / 22(0.0)$ & - & - \\
\hline & An. bellator & $0 / 9(0.0)$ & - & - \\
\hline & Subtotal & $0 / 31(0.0)$ & - & - \\
\hline \multirow{2}{*}{$1-C$} & An. cruzii & $0 / 1(0.0)$ & - & - \\
\hline & Subtotal & $0 / 1(0.0)$ & - & - \\
\hline \multirow{2}{*}{2} & An. albitarsis & $0 / 14(0.0)$ & - & - \\
\hline & Subtotal & $0 / 14(0.0)$ & - & - \\
\hline \multirow{5}{*}{3} & An. albitarsis & $0 / 1(0.0)$ & - & - \\
\hline & An. cruzii & $0 / 20(0.0)$ & - & - \\
\hline & An. galvaoi & $1 / 48(2.1)$ & $1 / 1(100.0)$ & P. falciparum \\
\hline & An. mediopunctatus & $0 / 42(0.0)$ & - & - \\
\hline & Subtotal & $1 / 111(0.9)$ & $1 / 1(100.0)$ & - \\
\hline \multirow{5}{*}{4} & An. albitarsis & $0 / 13(0.0)$ & - & - \\
\hline & An. cruzii & $0 / 4(0.0)$ & - & - \\
\hline & An. strodei & $0 / 1(0.0)$ & - & - \\
\hline & An. triannulatus & $0 / 5(0.0)$ & - & - \\
\hline & Subtotal & $0 / 23(0.0)$ & - & - \\
\hline \multirow{6}{*}{5} & An. cruzii & 4/207 (1.9) & $1 / 4(25.0)$ & P. vivax \\
\hline & An. cruzii & 18/207 (8.7) & $15 / 18(83.0)$ & P. falciparum \\
\hline & Subtotal & 22/207 (10.6) & $16 / 22(72.7)$ & - \\
\hline & Total P. vivax & $4 / 480(0.8)$ & $1 / 4(25.0)$ & \\
\hline & Total P. falciparum & $21 / 480(4.4)$ & $16 / 21(76.2)$ & \\
\hline & Total & $25 / 480(5.2)$ & $17 / 25(68.0)$ & \\
\hline
\end{tabular}

\footnotetext{
${ }^{a}$ Morphological identification of the specimens tested positive for Plasmodium was confirmed by DNA COI barcode sequences.
}

${ }^{b}$ Plasmodium species identified in Anopheles mosquitoes by real-time PCR and/or conventional PCR plus DNA sequencing with species-specific primers [21].

[38]. Anopheles bellator, An. cruzii, and An. homunculus are the most important vectors of $P$. vivax involved in the dynamics of the bromeliad-malaria in the Atlantic forest [39].

In the present study, however, results of Anopheles mosquitoes captured in seven landscapes, which have been distinctly modified by human activities, revealed a high prevalence of An. cruzii infected with P. falciparum, contrasting with a low proportion of infection by $P$. vivax. In addition, other species of the subgenus Nyssorhynchus of Anopheles were found infected with P. falciparum (An. triannulatus, An. strodei and An. galvaoi). The high prevalence in An. cruzii and those findings of An. galvaoi, An. triannulatus and $A n$. strodei infected with $P$. falciparum represent, therefore, a challenge to the bromeliad-malaria paradigm. The found of An. cruzii as a potential vector of P. falciparum, and that species of another subgenus of Anopheles also may be involved in the malaria dynamics, in landscapes with different patterns of intermixed natural and human-modified environments of the southeastern Atlantic forest, suggest that residual malaria transmission in that region is complex and challenging. Therefore, malaria dynamics in that region may result from simultaneous cycles involving a range of anopheline species and, likely, monkeys as reservoirs.

Recent studies suggest that the bromeliad-malaria paradigm alone cannot explain the residual malaria in the Atlantic forest. For instances, there are several evidences of complex biological cycles involving different Plasmodium species and anopheline vectors. Duarte et al. [10] found 
Table 3 Analysis of the binomial probability distribution of anopheline-P. falciparum infection according to landscape or species or traps, Atlantic forest, Brazil, August-November 2012

\begin{tabular}{|c|c|c|c|c|}
\hline Landscape & Positive (k) & Tested (n) & $\begin{array}{l}\text { Probability } \\
(\mathrm{P})^{\mathrm{a}}\end{array}$ & $\begin{array}{l}1-P \\
(k=0)\end{array}$ \\
\hline $1-\mathrm{A}$ & 2 & 93 & 0.138 & 0.985 \\
\hline $1-B$ & 0 & 31 & 0.248 & $0.752^{c}$ \\
\hline $1-C$ & 0 & 1 & 0.956 & $0.044^{c}$ \\
\hline 2 & 0 & 14 & 0.533 & $0.467^{c}$ \\
\hline 3 & 1 & 111 & $0.035^{b}$ & 0.993 \\
\hline 4 & 0 & 23 & 0.355 & $0.645^{c}$ \\
\hline 5 & 18 & 207 & $0.003^{b}$ & 0.997 \\
\hline Species & Positive (k) & Tested (n) & $\begin{array}{l}\text { Probability } \\
(\mathrm{P})^{\mathrm{a}}\end{array}$ & $\begin{array}{l}1-P \\
(k=0)\end{array}$ \\
\hline An. albitarsis & 0 & 28 & 0.284 & $0.716^{c}$ \\
\hline An. bellator & 0 & 9 & 0.667 & $0.333^{c}$ \\
\hline An. cruzii & 18 & 260 & $0.018^{b}$ & 0.999 \\
\hline An. fluminensis & 0 & 3 & 0.874 & $0.126^{c}$ \\
\hline An. galvaoi & 1 & 48 & 0.255 & 0.885 \\
\hline An. mediopunctatus & 0 & 42 & 0.151 & 0.849 \\
\hline An. strodei & 1 & 73 & 0.126 & 0.963 \\
\hline An. triannulatus & 1 & 17 & 0.364 & $0.535^{c}$ \\
\hline Traps & Positive (k) & Tested (n) & $\begin{array}{l}\text { Probability } \\
(\mathrm{P})^{\mathrm{a}}\end{array}$ & $\begin{array}{l}1-P \\
(k=0)\end{array}$ \\
\hline$\overline{C D C-L T}$ & 0 & 38 & 0.181 & 0.819 \\
\hline Shannon & 21 & 442 & $0.083^{b}$ & 1 \\
\hline
\end{tabular}

${ }^{a}$ An a priori probability of success $(\mathrm{k} / \mathrm{n})$ in each trial equals to 0.044 , which was the overall prevalence of anopheline- $P$. falciparum infection obtained herein (21/480), was assumed.

${ }^{\mathrm{b}}$ This result was statistically significant (level of significance $<0.05$ ).

'This result shows that the statistical power was low $(<0.80)$.

that An. (Nys.) lutzi and An. triannulatus from anthropic zones were infected with $P$. vivax; An. strodei from transition zones (areas between sylvatic and anthropic zones) was positive for P. malariae and An. cruzii from sylvatic and anthropic regions tested positive for $P$. vivax and $P$. malariae. Similarly, Neves et al. [20] demonstrated that specimens of An. (Ano.) fluminensis, An. (Ano.) pseudomaculipes/maculipes and An. cruzii captured in a coastal area of an Atlantic forest reserve were infected with $P$. vivax and $P$. malariae. In addition, $P$. falciparum DNA has been reported in asymptomatic human residents in the mountainous regions of the Atlantic forest, in Espírito Santo state [18]. Furthermore, Yamasaki et al. [19] hypothesized that interacting human and zoonotic cycles of malaria transmission, including simians as potential reservoirs, occur in the Atlantic forest region.

Additionally, in the present work Plasmodium-infected anophelines were found in three out of seven landscapes composed of intermixed natural and human-modified environments. It should be mentioned here, however, that the sample sizes obtained in the negative landscapes were not large enough to exclude the possibility of $P$. falciparum circulation in the areas. These results also suggest a possible gradient between human environment modification and the occurrence of malaria. For instance, landscape 5, with a forest/rural environment ratio of 3:1, had the highest proportion of $P$. falciparum-infected anophelines ( $8.7 \%$ of $A n$. cruzii, significantly higher than expected by chance); landscape 1-A (forest/rural ratio of 1.9:1) had 2.2\% of Nyssorhynchus species infected with P. falciparum, an outcome expected by chance; finally, landscape 3 (with forest/rural ratio of $0.8: 1$ ) had a lower than expected proportion of $P$. falciparum-infected anophelines ( $0.9 \%$ of infected Nyssorhynchus species). In addition, landscape 5 is located in the same geographical region of São Paulo state where Maselli et al. [21] found a surprisingly high prevalence of subclinical $P$. falciparum infection among asymptomatic blood donors. Previous work by [40-42] also suggests that landscapes intermixing natural and human modified environments may favor malaria transmission.

The occurrence of major human infectious diseases has long been related to landscape modification, particularly by agriculture, which suggests that human modification of natural environments significantly increases the risk of infectious disease outbreaks, causing profound changes in the transmission dynamics of such infections, and possible evolutionary modifications in the pathogens [43]. Recent evidence on the possible origin of human $P$. falciparum in gorillas demonstrates the importance of such evolutionary pathogen modifications in response to evolving malaria transmission dynamics [44-47]. Krief et al. [48] proposes that P. falciparum may have evolved as a species in Pan paniscus (bonobos) and subsequently colonized humans by a host-switch. In addition, based on results of phylogenetic analysis, they assumed that Pan troglodytes (chimpanzees) and bonobo primates can act as reservoirs for all Plasmodium species to which humans are susceptible. On the other hand, the high prevalence of $P$. falciparum subclinical infections in blood donors living in forested areas of São Paulo [21] and the present findings of a high prevalence of $P$. falciparum in infected An. cruzii and other Anopheles (Nyssorhynchus) species in the same region, possibly indicate that this Plasmodium species may have adapted to monkeys as main reservoirs, in the Atlantic forest. Additional evidence supporting this hypothesis is the high genetic similarity between the DNA sequences from positive mosquitoes captured in Atlantic forest remains in the present study with those previously obtained from wild monkeys in Rondônia and deposited in the GenBank [35]. Of course, further evidence such as identification and genomic characterization of the parasites in wild monkeys of the Atlantic forest remains 
and the completion of socio-ecological surveys specifically designed to test such hypothesis are necessary to confirm these preliminary findings.

\section{Conclusions}

The present study adds new and strong evidence to support the hypothesis of coexisting cycles of enzootic and human malaria, determining the residual malaria transmission dynamics in areas of the southeastern Atlantic forest. It also indicates that the bromeliad-malaria paradigm is not the only explanation for the dynamics of residual malaria transmission in the southeastern Brazilian Atlantic forest. Perhaps more important than this, is the recognition of the need for future studies focusing on both the evolutionary origin of $P$. falciparum that is circulating among different Anopheles species in the Atlantic forest and on the effects of different gradients of intermixed forest and human modified environments on malaria transmission in that region.

\section{Additional files}

Additional file 1: Field design. Schematic illustration representing types and position in the landscape of anopheline collection traps: 1) CDC-LT in the canopy in forest, 2) CDC-LT on the ground in forest, 3) CDC-LT in the canopy in forest margin, 4) CDC-LT on the ground in forest margin, 5) CDC-LT on the ground in open area, 6) CDC-LT with Octenol and $\mathrm{CO}_{2}$, and 7) Shannon trap. Trap drawings are out of scale and were modified from [25], Shannon, and [49], CDC-LT.

Additional file 2: CDC-LT and Shannon traps utilized for field collections per landscape, Atlantic forest, Brazil, August-November 2012.

Additional file 3: Successful amplification of Plasmodium species in Anopheles species per type of PCR method, Atlantic forest, Brazil, August-November 2012.

Additional file 4: Description of the sequenced Plasmodium-infected Anopheles species, Atlantic forest, Brazil, August-November 2012.

\section{Abbreviations}

BLAST: Basic local alignment search tool; COI: Cytochrome oxidase 1; CSP: Circumsporozoite protein; DNA: Deoxyribonucleic acid; EDTA: Ethylenediamine tetraacetic acid; GIS: Geographic information system; Landsat TM: Land remote sensing satellite thematic mapper; PCR: Polymerase chain reaction.

\section{Competing interests}

The authors declare that they have no competing interests.

\section{Authors' contributions}

GZL, MNB, EM, and MAMS conceived the idea. GZL, DL, SPB, and MAMS participated in the study design. DL, LAF, TMPO, and GZL performed the experiments with supervision of SPB, LMFM and MAMS. SPB, GZL and MAMS provided reagents and equipment. GZL, MNB, DL, JEC, EM, SPB, and MAMS analyzed and interpreted the data. MAMS, GZL, JEC, MNB wrote the manuscript with the help of DL, EM, and SPB. All authors read and approved the final version.

\section{Acknowledgments}

We are in debited to Marcelo Jacobs-Lorena for providing Anopheles mosquitoes infected with Plasmodium; Marcelo Urbano Ferreira for Plasmodium samples used as positive controls for the PCRs; financial support from Fundação de Amparo à Pesquisa do Estado de São Paulo
(FAPESP Grant 2011/20397-7) and Conselho Nacional de Desenvolvimento Científico e Tecnológico (CNPq no. 301666/2011-3) to MAMS; financial support from FAPESP (Grant 2009/53141-5) and CNPq to SBP. GZL had a postdoctorate fellowship from FAPESP (Grant 2012/09939-5), and is currently supported by FAPESP (Grant 2014/09774-1).

\section{Author details}

'Departamento de Epidemiologia, Faculdade de Saúde Pública da Universidade de São Paulo, São Paulo, SP 01246-904, Brazil. ${ }^{2}$ Laboratório de Informática Médica (LIM 01), Faculdade de Medicina da Universidade de São Paulo, São Paulo, SP 05405-000, Brazil. ${ }^{3}$ Divisão de Doenças Infecciosas, Hospital São Paulo, Escola Paulista de Medicina, Universidade Federal de São Paulo, São Paulo, SP 04024-002, Brazil. “'Laboratório de Genética e Hematologia Molecular (LIM 31), Faculdade de Medicina da Universidade de São Paulo, São Paulo, SP 05403-000, Brazil. ' Divisão de Pesquisa, Fundação Pró-Sangue Hemocentro de São Paulo, Faculdade de Medicina da Universidade de São Paulo, São Paulo, SP 05403-000, Brazil. 'Department of Health, Wadsworth Center, Slingerlands, NY 12159, USA. ${ }^{7}$ Department of Biomedical Sciences, School of Public Health, State University of New York-Albany, Albany, NY 12222, USA.

Received: 23 September 2014 Accepted: 4 April 2015

Published online: 25 April 2015

\section{References}

1. Lutz A. Waldmosquitos und waldmalaria. Centralbl Bakt. 1903;33:282-92.

2. Deane LM. Simian Malaria in Brazil. Mem Inst Oswaldo Cruz. 1992;87:1-20.

3. Gadelha P. From "forest malaria" to "bromeliad malaria": a case-study of scientific controversy and malaria control. Parassitologia. 1994;36:175-95.

4. Branquinho MS, Marrelli MT, Curado I, Natal D, Barata JM, Tubaki RM, et al. Infecção de Anopheles (Kerteszia) cruzii por Plasmodium vivax e Plasmodium vivax variante VK247 nos municípios de São Vicente e Juquitiba, São Paulo. Rev Panam Salud Publica. 1997;2:189-93.

5. Curado I, Malafronte RS, Duarte AMRC, Kirchgatter K, Branquinho MS, Galati EAB. Malaria epidemiology in low-endemicity areas of the Atlantic forest in the Vale do Ribeira, Sao Paulo, Brazil. Acta Trop. 2006;100:54-62.

6. Rezende HR, Soares RM, Cerutti Jr C, Alves IC, Natal D, Urbinatti PR, et al. Entomological characterization and natural infection of anophelines in an area of the Atlantic forest with autochthonous malaria cases in mountainous region of Espírito Santo State, Brazil. Neotrop Entomol. 2009;38:272-80.

7. Costa DC, Cunha VP, Assis GMP, Souza Jr JC, Hirano ZMB, Arruda ME, et al. Plasmodium simium/Plasmodium vivax infections in southern brown howler monkeys from the Atlantic forest. Mem Inst Oswaldo Cruz. 2014;109:641-3.

8. Marques TC, Bourke BP, Laporta GZ, Sallum MAM. Mosquito (Diptera, Culicidae) assemblages associated with Nidularium and Vriesea bromeliads in Serra do Mar, Atlantic forest, Brazil. Parasit Vectors. 2012;5:41.

9. Ribeiro AF, Urbinatti PR, Duarte AMRC, Paula MB, Pereira DM, Mucci LF, et al. Mosquitoes in degraded and preserved areas of the Atlantic forest and potential for vector-borne disease risk in the municipality of São Paulo, Brazil. J Vector Ecol. 2012;37:316-26.

10. Duarte AMRC, Pereira DM, Paula MB, Fernandes A, Urbinatti PR, Ribeiro AF, et al. Natural infection in anopheline species and its implications for autochthonous malaria in the Atlantic forest in Brazil. Parasit Vectors. 2013;6:58.

11. Smith LB. Bromeliad Malaria. Rep Smithson Inst. 1952;1953:385-98.

12. Pina-Costa A, Brasil P, Di Santi SM, de Araujo MP, Suárez-Mutis MC, Santelli AC, et al. Malaria in Brazil: what happens outside the Amazonian endemic region. Mem Inst Oswaldo Cruz. 2014;109:618-33.

13. Oliveira-Ferreira J, Lacerda MV, Brasil P, Ladislau JL, Tauil PL, Daniel-Ribeiro CT. Malaria in Brazil: an overview. Malar J. 2010;9:115.

14. Barreto ML, Teixeira MG, Bastos Fl, Ximenes R, Barata R, Rodrigues L. Successes and failures in the control of infectious diseases in Brazil: social and environmental context and research needs. Lancet. 2011;377:1877-89.

15. Miguel RB, Peiter PC, Albuquerque H, Coura JR, Moza PG, Pina-Costa A, et al. Malaria in the state of Rio de Janeiro, Brazil, an Atlantic forest area: an assessment using the health surveillance service. Mem Inst Oswaldo Cruz. 2014; 109:634-40

16. Duarte AMRC, Porto MA, Curado I, Malafronte RS, Hoffmann EH, Oliveira SG, et al. Widespread occurrence of antibodies against circumsporozoite protein 
and against blood forms of Plasmodium vivax, $P$. falciparum and $P$. malariae in Brazilian wild monkeys. J Med Primatol. 2006:35:87-96.

17. Duarte AMRC, Malafronte RS, Cerutti Jr C, Curado I, Paiva BR, Maeda AY, et al. Natural Plasmodium infections in Brazilian wild monkeys: Reservoirs for human infections? Acta Trop. 2008;107:179-85.

18. Cerutti Jr C, Boulos M, Coutinho AF, Hatab MCLD, Falqueto A, Rezende HR, et al. Epidemiologic aspects of the malaria transmission cycle in an area of very low incidence in Brazil. Malar J. 2007;6:33.

19. Yamasaki T, Duarte AMRC, Curado I, Summa ME, Do Valle DD, Wunderlich G, et al. Detection of etiological agents of malaria in howler monkeys from Atlantic forests, rescued in regions of São Paulo city, Brazil. J Med Primatol. 2011;40:392-400.

20. Neves A, Urbinatti PR, Malafronte RS, Fernandes A, Paganini WS, Natal D. Malaria outside the Amazon region: natural Plasmodium infection in anophelines collected near an indigenous village in the Vale do Rio Branco, Itanhaém, SP, Brazil. Acta Trop. 2013;125:102-6.

21. Maselli LMF, Levy D, Laporta GZ, Monteiro AM, Fukuya LA, Ferreira Da Cruz F, et al. Detection of Plasmodium falciparum and Plasmodium vivax subclinical infection in non-endemic region: implications for blood transfusion and malaria epidemiology. Malar J. 2014;13:224.

22. Mendrone Jr A, Cerutti C, Levi JE, Boulos M, Arroyo Sanchez MC, Malafronte RS, et al. Unexpected detection of Plasmodium vivax and Plasmodium falciparum in asymptomatic blood donors: fact or artifact? Malar J. 2014;13:336.

23. Sallum MAM, Daniel-Ribeiro CT, Laporta GZ, Ferreira-da-Cruz MF, Maselli LM, Levy D, et al. Finding connections in the unexpected detection of Plasmodium vivax and Plasmodium falciparum DNA in asymptomatic blood donors: a fact in the Atlantic forest. Malar J. 2014;13:337.

24. Spatial Pattern Analysis Program for Categorical and Continuous Maps. http://www.umass.edu/landeco/research/fragstats/fragstats.html. Accessed in 13 Jun 2013.

25. Forattini OP. Culicidologia Médica. São Paulo, SP, Brazil: EDUSP; 2002.

26. Foster PG, Bergo ES, Bourke BP, Oliveira TMP, Nagaki SS, Sant'Ana DC, et al. Phylogenetic analysis and DNA-based species confirmation in Anopheles (Nyssorhynchus). PLoS One. 2013;8:e54063.

27. Basic Local Alignment Search Tool. http://blast.ncbi.nlm.nih.gov/Blast.cgi. Accessed in 20 Aug 2014.

28. Miller SA, Dykes DD, Polesky HF. A simple salting out procedure for extracting DNA from human nucleated cells. Nucleic Acids Res. 1998;16:1215.

29. Foley DH, Harrison G, Murphy JR, Dowler M, Rueda LM, Wilkerson RC. Mosquito bisection as a variable in estimates of PCR-derived malaria sporozoite rates. Malaria J. 2012;11:145.

30. Perandin F, Manca N, Calderaro A, Piccolo G, Galati L, Ricci L, et al. Development of a real-time PCR assay for detection of Plasmodium falciparum, Plasmodium vivax, and Plasmodium ovale for routine clinical diagnosis. J Clin Microbiol. 2004;42:1214-9.

31. Sanger F, Nicklen S, Coulson AR. DNA sequencing with chain-terminating inhibitors. Proc Natl Acad Sci U S A. 1977;74:5463-7.

32. Norman GR, Treiner DL. Biostatistics, The Bare Essentials. St. Louis, Missouri; USA: Mosby-Year Book; 1994.

33. Laporta GZ, Ramos DG, Ribeiro MC, Sallum MAM. Habitat suitability of Anopheles vector species and association with human malaria in the Atlantic forest in south-eastern Brazil. Mem Inst Oswaldo Cruz. 2011;106:239-45.

34. Couto RD'A, Latorre MRDO, Di Santi SM, Natal D. Autochthonous malaria notified in the State of São Paulo: clinical and epidemiological characteristics from 1980 to 2007. Rev Soc Bras Med Trop. 2010;43:52-8.

35. Araújo MS, Messias MR, Figueiró MR, Gil LH, Probst CM, Vidal NM, et al. Natural Plasmodium infection in monkeys in the state of Rondônia (Brazilian western Amazon). Malar J. 2013;12:180.

36. Forattini OP, Kakitani I, Massad E, Marucci D. Studies on mosquitoes (Diptera: Culicidae) and anthropic environment. 11 - biting activity and blood-seeking parity of Anopheles (Kerteszia) in South-Eastern Brazil. Rev Saude Publica. 1996;30:107-14.

37. Downs WG, Pittendrigh CS. Bromelian malaria in Trinidad, British West Indies. Am J Trop Med Hyg. 1946;26:47-66.

38. Zavortink TJ. Mosquito studies (Diptera, Culicidae) XXIX. A review of the subgenus Kerteszia of Anopheles. Contrib Am Entomol Inst. 1973;9:1-54.
39. Marrelli MT, Malafronte RS, Sallum MAM, Natal D. Kerteszia subgenus of Anopheles associated with the Brazilian Atlantic rainforest: current knowledge and future challenges. Malar J. 2007;6:127.

40. Wayant NM, Maldonado D, Arias AR, Cousiño B, Goodin DG. Correlation between normalized difference vegetation index and malária in a subtropical rain forest undergoing rapid anthropogenic alteration. Geospat Health. 2010;4:179-90.

41. Lambin EF, Tran A, Vanwambeke SO, Linard C, Soti V. Pathogenic landscapes: interactions between land, people, disease vectors, and their animal hosts. Int J Health Geogr. 2010;9:54.

42. Kar NP, Kumar A, Singh OP, Carlton JM, Nanda N. A review of malaria transmission dynamics in forest ecosystems. Parasit Vectors. 2014;7:265

43. Wolfe ND, Dunavan CP, Diamond J. Origins of major human infectious diseases. Nature. 2007;447:279-83.

44. Liu W, Li Y, Learn GH, Rudicell RS, Robertson JD, Keele BF, et al. Origin of the human malaria parasite Plasmodium falciparum in gorillas. Nature. 2010;467:420-5.

45. Rayner JC, Liu W, Peeters M, Sharp PM, Hahn BH. A plethora of Plasmodium species in wild apes: a source of human infection? Trends Parasitol. 2011;27:222-9.

46. Sharp PM, Rayner JC, Hahn BH. Evolution: Great apes and zoonoses. Science. 2013:340:284-6.

47. Sundararaman SA, Liu W, Keele BF, Learn GH, Bittinger K, Mouacha F, et al. Plasmodium falciparum-like parasites infecting wild apes in southern Cameroon do not represent a recurrent source of human malaria. Proc Natl Acad Sci U S A. 2013;110:7020-5.

48. Krief S, Escalante AA, Pacheco MA, Mugisha L, André C, Halbwax M, et al. On the diversity of malaria parasites in African apes and the origin of Plasmodium falciparum from Bonobos. PLoS Pathog. 2010;6, e1000765.

49. Service MW. Mosquito Ecology. London, UK: Chapman \& Hall; 1993.

\section{Submit your next manuscript to BioMed Central and take full advantage of:}

- Convenient online submission

- Thorough peer review

- No space constraints or color figure charges

- Immediate publication on acceptance

- Inclusion in PubMed, CAS, Scopus and Google Scholar

- Research which is freely available for redistribution 